\title{
Mind, Brain, and Education in Socioeconomic Context
}

\section{Martha J. Farah \\ Introduction}

Ten years ago, when I was just becoming interested in the relation between child development and socioeconomic status, I attended a small workshop sponsored by the McDonnell Foundation to discuss new directions in developmental cognitive neuroscience. At the time I knew virtually nothing about development or SES but, since the meeting was so small and informal, I decided to present some ideas on the topic of "cognitive developmental neuro-sociology" for the sake of getting feedback from the experts present. Although everyone gave me a good-natured hearing, one person took me aside afterward and offered a wealth of information, advice, and encouragement. He continued to educate me through subsequent correspondence and a visit to his lab in Toronto. That person was Robbie Case. By guiding me to relevant literatures on socioeconomic disparities and childhood development, of which I had been embarrassingly ignorant, and by encouraging me to try working in this area for which I was little prepared, he was instrumental in helping turn the vague musings of that small meeting into the program of empirical research described here.

What would a field with the inauspicious name "cognitive developmental neurosociology" be about? To me, it represented a new approach to the age-old problems of social stratification and the persistence of poverty. Why, in advanced societies that seem to offer opportunity for all, do some people remain poor? Why do many families remain poor across generations? These questions have occupied sociologists for as long as their field has existed, and have been answered in many ways.

Marxist approaches to the persistence of poverty emphasized purely economic factors that create and maintain social stratification (Marx, 1867). Functionalist accounts highlight the many ways in which society as a whole is served by the enduring presence of a lower class (e.g., Weber, 1923). The concept of a Culture of Poverty emphasizes causes within individuals and their subculture, rather than

M.J. Farah (凶)

Center for Cognitive Neuroscience, University of Pennsylvania, Philadelphia, PA, USA

e-mail: mfarah@psych.upenn.edu 
external societal forces, in perpetuating poverty across generations (Lewis, 1965). Each account undoubtedly captures some truth about the complex and multifactorial processes that confine children born of poor parents to lifelong poverty.

Cognitive neuroscience may offer yet another perspective on the problem by illuminating the ways in which the experience of growing up poor reduces people's ability to escape poverty. Neuroscience research on the effects of early experience on animal brain development suggests how childhood poverty might constrain human brain development. Specifically, the reduced opportunities for stimulating experience and increased stress of poverty would be expected to exert a negative influence on neurocognitive development. Without good neurocognitive development, intellectual and educational attainments are limited, which in turn limits upward socioeconomic mobility.

\section{Education, Socioeconomic Status, and Child Development}

In principle, education is an equalizer that provides all individuals in our society with the opportunity to fulfill their intellectual potential and prepare for worthwhile employment. In practice, these benefits of education are often less available to individuals of low socioeconomic status for a variety of reasons (see Arnold \& Doctoroff, 2003, for a review). Schools attended by low-SES students are generally less well funded than other schools. This results in lower quality education and worse educational outcomes for students at such schools (Phillips, Voran, Kisker, Howes, \& Whitebook, 1994; Pianta, La Paro, Payne, Cox, \& Bradley, 2002). Attitudes of teachers and parents also play a role, with lower and more negative expectations of lower SES students (Alexander, Entwistle, \& Thompson, 1987; Battin-Pearson et al., 2000; McLoyd, 1990). Finally, even before they enter school, low-SES children lag behind their middle-class counterparts by most measures of cognitive development (e.g., Bayley Infant Behavior Scales and IQ scores) and school readiness (e.g., preliteracy skills such as letter recognition) (Brooks-Gunn \& Duncan, 1997). They enter the school system in need of an enriched educational experience, but often their lack of preparation is simply compounded by an inadequate school system (Arnold \& Doctoroff, 2003).

The research summarized in this chapter is aimed at understanding the ways in which childhood poverty, including experiences prior to school entry, affect cognitive development. The correlations between SES and performance on standardized tests such as IQ tell us that SES must be related to brain development, as cognitive ability is a function of the brain. Yet little is currently known about the relationship between SES and brain development. Open questions include the specific neurocognitive systems that correlate with SES, the impact of these neurocognitive disparities on school readiness and school achievement, and the mechanisms by which these disparities emerge. The research summarized here includes work by me, my colleagues, and others, aimed at answering these open questions. 
Mind, Brain, and Education in Socioeconomic Context

\section{The Neurocognitive Profile of Childhood Poverty}

For a cognitive neuroscience approach to be helpful in understanding cognitive development in poverty, the relations between socioeconomic status and the brain must be relatively straightforward and generalizable. The first question to be addressed is therefore: Can we generalize about the neurocognitive correlates of socioeconomic status, that is, the specific neurocognitive systems that are, and are not, correlated with SES?

Although most research on SES and child development has involved relatively broad-spectrum measures of cognition such as IQ or school achievement, there is evidence that points more specifically to associations with language development and executive function. The literature on language development is the most extensive in this regard, documenting robust SES disparities in vocabulary and phonological awareness among other linguistic abilities (see Whitehurst, 1997, for a review). SES disparities in executive functions associated with prefrontal cortex have also been noted. In the one such study, Mezzacappa (2004) tested a large group of urban 6-year-olds of varying SES on a computerized task that allows different components of attention to be assessed (the Attention Network Task, Rueda et al., 2004). He found the strongest relation with SES in what he termed "executive attentional" processes. Lipina, Martelli, Vuelta, and Colombo (2005) studied the development of working memory and inhibitory control in infancy by administering Diamond's (1990) "A-not-B" protocol to healthy infants from poor and nonpoor families. They found a significant disparity between the two groups.

These studies tell us that language and executive function, two types of ability that reflect the operation of specific neural systems, develop differently in children depending on SES. However, these studies do not tell us whether the SES disparities in cognition are limited to these neurocognitive systems, whether other specific systems are also affected, or whether the SES disparity in neurocognitive development is global, affecting all systems. To answer this question, it is necessary to assess the development of a set of different neurocognitive systems together in the same children. This is what we have done in a series of three studies.

In an initial study, we compared the neurocognitive performance of 30 lowand 30 middle-SES African-American Philadelphia public school kindergarteners (Noble, Norman, \& Farah, 2005). The children were tested on a battery of tasks adapted from the cognitive neuroscience literature, designed to assess the functioning of five key neurocognitive systems. These systems are described briefly here:

- The Prefrontal/Executive system enables flexible responding in situations where the appropriate response may not be the most routine or attractive one, or where it requires maintenance or updating of information concerning recent events. It is dependent on prefrontal cortex, a late-maturing brain region that is disproportionately developed in humans. 
- The Left perisylvian/Language system is a complex, distributed system encompassing semantic, syntactic, and phonological aspects of language and dependent predominantly on the temporal and frontal areas of the left hemisphere that surround the Sylvian fissure.

- The Medial temporal/Memory system is responsible for one-trial learning, the ability to retain a representation of a stimulus after a single exposure to it (which contrasts with the ability to gradually strengthen a representation through conditioning-like mechanisms), and is dependent on the hippocampus and related structures of the medial temporal lobe.

- The Parietal/Spatial cognition system underlies our ability to mentally represent and manipulate the spatial relations among objects and is primarily dependent upon posterior parietal cortex.

- The Occipitotemporal/Visual cognition system is responsible for pattern recognition and visual mental imagery, translating image format visual representations into more abstract representations of object shape and identity, and reciprocally translating visual memory knowledge into image format representations (mental images).

Not surprisingly, in view of the literature on SES and standardized cognitive tests, the middle-SES children performed better than the low-SES children on the battery of tasks as a whole. Also consistent with the literature just reviewed, the Left perisylvian/Language system and the Prefrontal/Executive system showed substantial disparities between the low- and middle-SES kindergarteners. Indeed, the groups differed by over a standard deviation in their performance composite on language tests, and by over two thirds of a standard deviation in the executive function composite. The other neurocognitive systems tested did not differ significantly between low- and middle-SES children, and in fact differed significantly less than the first two.

In a subsequent study we attempted to replicate and extend these findings in an older group of children with a different set of tasks. We tested 60 middle-school students, half of low and half of middle SES, matched for age, gender, and ethnicity (Farah et al., 2006). These children completed a new set of tests designed to tap the same neurocognitive systems as the previous study. In addition, instead of considering "prefrontal/executive" to be a single system, we subdivided it into three subsystems each with its own tests:

- The Lateral prefrontal/Working memory system enables us to hold information "on line" to maintain it over an interval and manipulate it, and is primarily dependent on the lateral surface of the prefrontal lobes. (Note that this is distinct from the ability to commit information to long-term memory, which is dependent on the medial temporal cortex.)

- The Anterior cingulate/Cognitive control system is required when we must resist the most routine or easily available response in favor of a more task-appropriate response and is dependent on a network of regions within prefrontal cortex including the anterior cingulate gyrus. 
Mind, Brain, and Education in Socioeconomic Context

- The Ventromedial prefrontal/Reward processing system is responsible for regulating our responses in the face of rewarding stimuli, allowing us to resist the immediate pull of a attractive stimulus in order to maximize more long-term gains.

A second important difference between this and the previous study concerned the tests of the Medial temporal/Memory system. In both of the tasks used to assess memory in the previous study, the test phase followed immediately after the initial exposure to the stimuli and memory per se may not have been the limiting factor in performance. The tasks that we used in the second study included a longer delay between initial exposure to the stimuli to be remembered and later test.

As with the younger children, sizeable and significant SES disparities were observed for language and executive function. In addition, it was possible to discern which aspects of executive function were most sensitive to SES. The Lateral prefrontal/Working memory and Anterior cingulate/Cognitive control subsystems showed SES disparities. Finally, with a longer delay between exposure and test in the memory tasks, we also found a difference in the Medial tempo$\mathrm{ral} /$ Memory system. SES was not associated with significant differences in the Parietal/Spatial cognition system, the Occipitotemporal/Visual cognition system, or the Ventromedial prefrontal/Reward processing system.

Finally, we assessed neurocognitive profile in 150 first graders of varying ethnicities whose SES spanned a range from low through middle (Noble, McCandliss, \& Farah, 2007). As before, we used a battery of age-appropriate tasks designed to tap the different neurocognitive systems. Also as before, the Left perisylvian/Language system showed a highly significant relationship to SES, as did the Medial tempo$\mathrm{ral} /$ Memory system and the executive functions Lateral prefrontal/Working memory and Anterior cingulate/Cognitive control. In addition, there was an SES gradient in Parietal/Spatial cognition.

In sum, although the outcome of each study was different, there were also commonalities among them despite different tasks, different children, and different ages of testing. The most robust neurocognitive correlates of SES appear to involve the Left perisylvian/Language system, the Medial temporal/Memory system (insofar as SES effects were found in both studies that tested memory with an adequate delay) and the Prefrontal/Executive system, in particular its Lateral prefrontal/Working memory and Anterior cingulate/Cognitive control components. Children growing up in low-SES environments perform less well on tests that tax the functioning of these specific systems.

\section{Neurocognitive Development and Academic Achievement}

SES disparities in executive function, memory, and language would be expected to impact school success in a variety of ways, compounding the challenges faced by low-SES students in school. Abundant research has documented the importance 
of executive function for self-regulation and the importance of self-regulation, in turn, for school readiness and academic achievement more generally (e.g., Blair \& Razza, 2007; Case, 1992; McClelland et al., 2007; Mischel, Shoda, \& Rodriguez, 1989; Posner \& Rothbart, 2005). The importance of memory ability for learning is obvious. Even when conceptual rather than rote learning is the goal, the ability to retain the particulars of facts or illustrations supports students' more abstract understanding. Finally, language is not only a subject of study in school but the medium through which most knowledge and skills are taught.

One pathway through which language ability affects school success is through its influence on reading ability. Kim Noble addressed the roles of language ability and SES on schoolchildren's reading ability in her dissertation research. She pointed out that, of the many aspects of language predictive of early reading, the most powerful predictor is "phonological awareness" (Bradley \& Bryant, 1983; Wagner \& Torgesen, 1987). This refers to our ability to attend to the sound structure of the language, as when we judge whether or not two words rhyme. Given earlier findings that phonological awareness is correlated with SES (Noble et al., 2005; Noble et al., 2007; Wallach, Wallach, Dozier, \& Kaplan, 1977), we were led to ask: Does the SES gradient in phonological awareness account for the SES gradient in reading ability? By assessing SES, phonological awareness, and reading ability in the sample of first graders from our earlier study, we found that SES was correlated with reading ability above and beyond its correlation with phonological awareness.

Furthermore, SES and phonological awareness were not independent in their influences on early reading ability. At lower levels of SES, reading ability was well predicted by phonological awareness, whereas the relationship was weaker at higher levels of SES. Put another way, at higher levels of phonological awareness, all children mastered reading, whereas children with lower levels of phonological awareness were better readers if they came from higher levels of SES. The benefits of a higher SES background appear to buffer children against the effects of low phonological awareness (Noble, Farah, \& McCandliss, 2006). A subsequent imaging study clarified the nature of this buffering effect. It might have reflected better functioning of the visual word decoding regions of the brain or other compensatory strategies used with a given level of visual word decoding. Our fMRI evidence showed that the visual word decoding area itself (in the left fusiform gyrus) was more active for higher SES children at a given level of phonological awareness, suggesting that the enriched literacy environment of higher SES homes affects the neural bases of visual word decoding per se (Noble et al., 2006).

\section{Mechanism: Disentangling Causes and Effects}

Why do different aspects of brain function come to be associated with SES? Do the associations discussed so far reflect the effects of SES on brain development, or the opposite direction of causality? Perhaps families with higher innate language, 
Mind, Brain, and Education in Socioeconomic Context

executive, and memory abilities tend to acquire and maintain a higher SES. Given that the direction of causality is an empirical issue, what data bear on the issue?

The methods of behavioral genetics research can, in principle, tell us about the direction of causality in the association between SES and the development of specific neurocognitive functions. However, these methods have yet to be applied to that question. They have been applied to a related question, namely the heritability of IQ and SES. Cross-fostering studies of within- and between-SES adoption suggest that roughly half the IQ disparity in children is experiential (Capron \& Duyme, 1989; Schiff \& Lewontin, 1986). If anything, these studies are likely to err in the direction of underestimating the influence of environment because the effects of prenatal and early postnatal environment are included in the estimates of genetic influences in adoption studies. Additional evidence comes from studies of when, in a child's life, poverty was experienced. Within a given family that experiences a period of poverty, the effects are greater on siblings who were young during that period (Duncan, Brooks-Gunn, \& Klebanov, 1994), an effect that cannot be explained by genetics. In sum, multiple sources of evidence indicate that SES does indeed have an effect on cognitive development, although its role in the specific types of neurocognitive system development investigated here is not yet known.

Many different aspects of childhood SES could affect neurocognitive development. Some do so by their direct effects on the body and some by less direct psychological mechanisms. Three somatic factors have been identified as significant risk factors for low cognitive achievement by the Center for Children and Poverty (1997): inadequate nutrition, lead exposure, and substance abuse (particularly prenatal exposure).

The role of nutrition in SES disparities in brain development has been difficult to resolve because nutritional status is so strongly correlated with a host of other family and environmental variables likely to impact neurocognitive development, including all of the potential mechanisms of causation to be reviewed here. Although nutritional supplementation programs could in principle be used as an "experimental manipulation" of nutritional status alone, in practice these programs are often coupled with other, non-nutritional forms of enrichment or affect children's lives in non-nutritional ways which perpetuate the confound (e.g., children given school breakfast are less often late or absent). In addition, poor nutrition may synergize with other forms of childhood deprivation in impairing brain development. Iron-deficiency anemia is known to afflict about one quarter of low-income children in the United States (CHPNP 1998) and is known to impair brain development when severe.

Lead is a neurotoxin to which children of lower SES are more likely exposed. Even at relatively low levels of lead in the blood, under10 $\mu \mathrm{g} / \mathrm{dL}$, there is a systematic relationship between lead level and IQ (Surkan et al., 2007). As with nutrition, the effect of lead synergizes with other environmental factors and is more pronounced in low-SES children (Bellinger, Leviton, Waternaux, Needleman, \& Rabinowitz, 1987).

Prenatal substance exposure is a third factor that affects children of all SES levels but is disproportionately experienced by the poor. Maternal use of alcohol, tobacco, 
marijuana, and other drugs of abuse have been associated with adverse cognitive outcomes in children (Chasnoff et al., 1998). Although the highly publicized phenomenon of "crack babies" might lead one to view prenatal cocaine exposure as a major contributor to the SES disparities noted here, there is little evidence that it plays a role. In her 2001 review of the literature on this topic, Frank offered the following tentative conclusion, pending new evidence: "there is no convincing evidence that prenatal cocaine exposure is associated with developmental toxic effects that are different in severity, scope, or kind from the sequelae of multiple other risk factors. Many findings once thought to be specific effects of in utero cocaine exposure are correlated with other factors, including prenatal exposure to tobacco, marijuana, or alcohol and the quality of the child's environment" (p. 1613). Indeed, we recently compared the performance of cocaine exposed and nonexposed children on the task battery used by Farah et al. (2006) and found no differences (Hurt et al., submitted).

The set of potentially causative somatic factors just reviewed is far from complete. There are SES gradients in a wide variety of physical health measures, many of which could affect children's neurocognitive development through a variety of different mechanisms (Adler et al., 1994). In addition, the typical psychological experiences of childhood differ sharply between poor and nonpoor families, and these differences also contribute to the differing neurocognitive outcomes for the children of these families.

\section{Psychological Influences on Neurocognitive Development in Poverty}

As with potential physical causes, the set of potential psychological causes for the SES gap in cognitive achievement is large, and the causes are likely to exert their effects synergistically. One difference between low- and middle-SES families that seems predictable, even in the absence of any other information, is that low-SES children are likely to receive less cognitive stimulation than middle-SES children. Their economic status alone predicts that they will have fewer toys and books and less exposure to zoos, museums, and other cultural institutions because of the expense of such items and activities. This is indeed the case (Bradley, Corwyn, McAdoo, \& Garcia Coll, 2001) and has been identified as a mediator between SES and measures of cognitive achievement (Bradley \& Corwyn, 1999; Brooks-Gunn \& Duncan, 1997; McLoyd, 1998).

Such a mediating role is consistent with the results of neuroscience research with animals. Starting many decades ago, researchers began to observe the powerful effects of environmental stimulation on brain development. Animals reared in barren laboratory cages showed less well-developed brains by a number of different anatomical and physiological measures, compared with those reared in more complex environments with opportunities to climb, burrow, and socialize (van Praag, Kempermann, \& Gage, 2000, Rosenzweig, 2003). 
Mind, Brain, and Education in Socioeconomic Context

Other types of cognitive stimulation are also less common in low-SES homes, for example parental speech designed to engage the child in conversation (Hoff, 2003). The average number of hours of one-on-one picture book reading experienced by children prior to kindergarten entry has been estimated at 25 for low-SES children and between 1000 and 1700 for middle-SES children (Adams, 1990). In addition to material limitations, differing parental expectations and concerns also contribute to differences in the amount of cognitive stimulation experienced by low- and middleSES children (Lareau, 2003).

Another major difference in the lives of low- and middle-SES individuals concerns levels of stress, and this has been related to differences in child development (Evans \& English, 2002). The lives of low-SES individuals tend to be more stressful for a variety of reasons, some of which are obvious: concern about providing for basic family needs, dangerous neighborhoods, and little control over one's work life. Again, research bears out this intuition: Turner and Avison (2003) confirmed that lower SES is associated with more stressful life events by a number of different measures. The same appears to be true for children as well as adults, and is apparent in salivary levels of the stress hormone cortisol (Lupien et al., 2001).

Why is stress an important consideration for neurocognitive development? Psychological stress causes the secretion of stress hormones, which affect the brain in numerous ways (Gunnar \& Quevedo, 2007; McEwen, 2000). The immature brain is particularly sensitive to these effects. In basic research studies of rat brain development, rat pups are subjected to the severe stress of prolonged separation from the mother and stress hormone levels predictably climb. However, the effect of a brief handling (minutes per day), which also separates the animal from its mother, appears beneficial. Both prolonged maternal separation and brief handling affect later-life stress regulation ability and memory ability as a result of their impact on hippocampal development. The salutary effect of brief separations appears to result from the intensified nurturing behavior that follows the separation. The more a mother rat licks her pup following a brief stressor, the better regulated the pup's later response to stressors and the better its learning ability (Liu, Diorio, Day, Francis, \& Meaney, 2000). This suggests that the high stress of poverty will take a toll on children's brain development, especially the development of the Medial tempo$\mathrm{ral} /$ Memory system, but that differences in parenting may strongly modulate those effects.

Our current research is attempting to make use of the description of the SES disparities in specific neurocognitive systems to test hypotheses about causal pathways. Drawing on the earlier findings indicating robust SES differences in Perisylvian/Language and Medial temporal/Memory systems, we are now testing hypotheses concerning the determinants of individual differences in the development of these systems in children of low SES (Farah et al., in press).

The participants in this research were 110 low-SES middle-school students from a cohort of children enrolled at birth in a study of the effects of prenatal cocaine exposure (see Hurt et al., 1995). Approximately half of the children have been exposed to cocaine prenatally and half have not. Maternal use of cocaine as well as amphetamines, opiates, barbiturates, benzodiazepines, marijuana, alcohol, and 
tobacco are ascertained by interview and medical record review at time of birth and, for all but the last three, maternal and infant urine specimens.

As part of the ongoing study of these children, a research assistant visited the home of each child at ages 4 and 8 and administered the HOME (Home Observation and Measurement of Environment, Caldwell \& Bradley, 1984). The HOME includes an interview with the mother about family life and observations of the interactions between mother and child. The HOME has a number of different subscales relevant to different aspects of the child's experience. We combined a number of different subscales indicative of the amount of cognitive stimulation provided to the child to make a composite measure of Environmental Stimulation, and a number of different subscales indicative of the amount of social/emotional nurturance provided to the child to make a composite measure of Parental Nurturance. The subscales used for each composite, along with representative items, were as follows:

- The Environmental Stimulation composite for 4-year-olds was composed of Learning stimulation ("child has toys which teach color," "at least 10 books are visible in the apartment"), language stimulation ("child has toys that help teach the names of animals," "mother uses correct grammar and pronunciation"), academic stimulation ("child is encouraged to learn colors," "child is encouraged to learn to read a few words"), modeling ("some delay of food gratification is expected," "parent introduces visitor to child"), and variety of experience ("child has real or toy musical instrument," "child's art work is displayed some place in house"). For 8-year-olds, the subscales used for the cognitive stimulation composite were: Growth fostering materials and experiences ("child has free access to at least ten appropriate books," "house has at least two pictures of other type of art work on the walls"), provision for active stimulation ("family has a television, and it is used judiciously, not left on continuously," "family member has taken child, or arranged for child to go to a scientific, historical, or art museum within the past year"), family participation in developmentally stimulating experiences ("Family visits or receives visits from relatives or friends at least once every other week," "family member has taken child, or arranged for child to go, on a trip of more than 50 miles from his home").

- The Parental Nurturance composite for 4-year-olds: was composed of: Warmth and affection ("parent holds child close 10-15 minutes per day," "parent converses with child at least twice during visit") and acceptance ("parent does not scold or derogate child more than once," "parent neither slaps nor spanks child during visit"). For 8-year-olds, the subscales used were Emotional and verbal responsivity ("Child has been praised at least twice during past week for doing something," "parent responds to child's questions during interview"), encouragement of maturity ("family requires child to carry out certain self-care routines," "parents set limits for child and generally enforce them"), emotional climate ("parent has not lost temper with child more than once during previous week," "parent uses some term of endearment or some diminutive for child's name when talking about child at least twice during visit") and paternal involvement ("Father [or father substitute] regularly engages in outdoor recreation with child," "Child 
Mind, Brain, and Education in Socioeconomic Context

eats at least one meal per day, on most days, with mother and father [or mother and father figure]").

Two other variables with the potential to account for differences in neurocognitive development included in our analyses were maternal intelligence and prenatal substance exposure. The former was measured by the Weschler Adult Intelligence Scale-Revised (WAIS-R). Maternal IQ could influence child neurocognitive outcome by genetic mechanisms or by its effect on the environment and experiences provided by the mother for the child. Prenatal substance exposure was coded for analysis on an integer scale of $0-4$, with one point for each of the following substances: tobacco, alcohol, marijuana, and cocaine. Use of other substances was an exclusionary criterion.

We used statistical regression to examine the relations between the neurocognitive outcome measures and the predictor variables Environmental Stimulation, Parental Nurturance, maternal IQ, and polysubstance use, as well as the child's gender and age at the time of neurocognitive testing. Our results indicate that the development of different neurocognitive systems is affected by different variables.

Children's performance on the tests of Left perisylvian/Language was predicted by average Environmental Stimulation. This was the sole factor identified as predicting language ability by forward stepwise regression, and one of two factors identified by backward stepwise regression, along with the child's age. In contrast, performance on tests of Medial temporal/Memory ability was predicted by average Parental Nurturance. This was the sole factor identified as predicting memory ability by forward stepwise regression and one of three factors identified by backward stepwise regression, along with the child's age and prenatal substance exposure. The relation between memory and Parental Experience is consistent with the animal research cited earlier (Liu et al., 2000).

Our analyses did not reveal any systematic relation of the predictor variables considered here to Lateral prefrontal/Working memory or Anterior cingulate/Cognitive control function.

The relation between life experience and brain development for human beings is undoubtedly more complex than for animals, but we can nevertheless be guided by the animal research literature in formulating hypotheses to test. So far, the use of this strategy has shown that different aspects of life experience, cognitive stimulation, and parental buffering of stress act on brain development by different pathways and affect the different neurocognitive systems to different degrees.

\section{Conclusions}

Educators are increasingly incorporating the ideas and findings of neuroscience into their work, a trend that Robbie Case both foresaw and helped to bring about. Our growing understanding of normal brain development and atypical brain development is forming the basis for new and more effective educational practice. With 
regard to normal brain development, cognitive neuroscientists have only recently shifted from the study of commonalities among brains to the study of individual differences in brain function. Educators, who must teach students of varying ability, motivation, and cognitive style, will presumably not wait as long to apply the cognitive neuroscience of individual differences in their work.

The findings summarized in this chapter concern a major cause of individual differences in school readiness and academic performance, namely SES. The different kinds of childhood experience that students of lower and higher SES bring into the classroom affects what they learn there. Reciprocally, the different kinds of schools attended by children of lower and higher SES also affect the potential for learning. The neural mechanisms involved in these processes are important subjects for future research in neuroscience and education. Of course, it does not take a proverbial rocket scientist or, for that matter, a neuroscientist to realize that children should have access to stimulating experiences, be protected from high levels of stress, and go to good schools. Nevertheless, a better understanding of the ways in which childhood experience and classroom instruction shape brain function will suggest new ways of preventing and remediating some of the disadvantages suffered by poor children.

\section{References}

Adams, M. J. (1990). Learning to read: Thinking and learning about print. Cambridge, MA: MIT Press.

Adler, N. E., Boyce, T., Chesney, M. A., Cohen, S., Folkman, S., Kahn, R. L., et al. (1994). Socioeconomic status and health: The challenge of the gradient. American Psychologist, 49, $15-24$.

Alexander, K., Entwisle, D., \& Thompson, M. (1987). School performance, status relations, and the structure of sentiment: Bringing the teacher back in. American Sociological Review, 52, 665-682.

Arnold, D. H., \& Doctoroff, G. L. (2003). The early education of socioeconomically disadvantaged children. The Annual Review of Psychology, 517-545.

Battin-Pearson, S., Newcomb, M. D., Abbott, R. D., Kill, K. G., Catalano, R. F., Hawkins, J. D. (2000). Predictors of early high-school drop-out: A test of five theories. Journal of Education and Psychology, 92, 568-582.

Bellinger, D., Leviton, A., Waternaux, C., Needleman, H., \& Rabinowitz, C. (1987). Longitudinal analyses of prenatal and postnatal lead exposure and early cognitive development. New England Journal of Medicine, 316, 1037-1043.

Blair, C. \& Razza, R. P. (2007). Relating effortful control, executive function, and false-belief understanding to emerging math and literacy ability in kindergarten. Child Development, 78, 647-663.

Bradley, L., \& Bryant, P. E. (1983). Categorizing sounds and learning to read - a causal connection. Nature, 301, 419-421.

Bradley, R. H., \& Corwyn, R. F. (1999). Parenting. In C. L. B. Tamis-Lemonda (Ed.), Child Psychology: A Handbook of Contemporary Issues (pp. 339-362). New York: Psychology Press.

Bradley, R. H., Corwyn, R. F., McAdoo, H. P. \& Garcia Coll C. (2001) The home environments of children in the United States. Part 1: Variations by age, ethnicity, and poverty-status. Child Development, 72, 1844-1867. 
Mind, Brain, and Education in Socioeconomic Context

Brooks-Gunn, J., \& Duncan, G. J. (1997). The effects of poverty on children. The Future of Children, 7, 55-71.

Caldwell, B. M., \& Bradley, R. H. (1984). Home Observation for Measurement of the Environment $(H O M E)$. Little Rock, AR: University of Arkansas.

Capron, C., \& Duyme, M. (1989). Assessment of effects of socio-economic status on IQ in a full cross-fostering study. Nature, 340, 552-554.

Case, R. (1992). The role of the frontal lobes in the regulation of cognitive development. Brain and Cognition, 20, 51-73.

Chasnoff, I. J., Anson, A., Hatcher, R., Stenson, H., Iaukea, K., \& Randolph, L. (1998). Prenatal exposure to cocaine and other drugs. Outcome at four to six years. Annals of the New York Academy of Sciences, 846, 314-328.

Diamond, A. (1990). The development and neural bases of memory functions as indexed by the $\mathrm{A}(\mathrm{not}) \mathrm{B}$ and delayed response tasks in human infants and infant monkeys. The Development and Neural Bases of Higher Cognitive Functions. A. Diamond. New York: New York Academy of Science, 267-317.

Duncan, G. J., Brooks-Gunn, J., \& Klebanov, P. K. (1994). Economic deprivation and earlychildhood development. Child Development, 65, 296-318.

Evans, G. W., \& English, K. (2002). The environment of poverty: Multiple stressor exposure, psychophysiological stress, and socioemotional adjustment. Child Development.

Farah, M. J., Shera, D. M., Savage, J. H., Betancourt, L., Giannetta, J. M., Brodsky, N. L., et al. (2006). Childhood poverty: Specific associations with neurocognitive development. Brain Research, 1110, 166-174.

Farah, M. J., Betancourt, L., Shera, D. M., Savage, J. H., Giannetta, J. M., Brodsky, N. L., et al. (in press). Environmental stimulation, parental nurturance and cognitive development in humans. Developmental Science.

Frank, D. A, Augustyn, M., Knight, W. G., Pell, T., \& Zuckerman, B. (2001). Growth, development, and behavior in early childhood following prenatal cocaine exposure: A systematic review. Journal of the American Medical Association, 285, 1613-1625.

Gunnar, M. R. \& Quevedo, K. (2007). The neurobiology of stress and development. In S. Fiske (Ed.) Annual Review of Psychology, 58, 145-174.

Hoff, E. (2003). The specificity of environmental influence: Socioeconomic status affects early vocabulary development via maternal speech. Child Development, 74, 1368-1378.

Hurt, H., Betancourt, L., Malmud, E. K., Shera, D. M., Giannetta, J. M., Brodsky, N. L., et al. (submitted). Effects of prenatal cocaine exposure at middle school age: A neurocognitive systems analysis.

Kass, L. (2003). Beyond therapy - biotechnology and the pursuit of happiness. New York: Harper Collins.

Lareau, A. (2003). Unequal childhoods: Class, race and family life. Berkeley, CA: University of California Press.

Lewis, O. (1965). La Vida. New York: Random House.

Lipina, S. J., Martelli, M. I., Vuelta, B. L., \& Colombo, J. A. (2005). Performance on the A-notB task of Argentinean infants from unsatisfied basic needs homes. Interamerican Journal of Psychology, 39, 49-60.

Liu, D., Diorio, J., Day, J. C., Francis, D. D., \& Meaney, M. J. (2000). Maternal care, hippocampal synaptogenesis and cognitive development in rats. Nature Neuroscience, 3(8), 799-806.

Lupien, S. J., S. King, et al. (2001). Can poverty get under your skin? Basal cortisol levels and cognitive function in children from low and high socioeconomic status. Development and Psychopathology, 13, 653-676.

Marx, K. (1976 (first published in 1867)). Capital (Vol. I). New York: Penguin.

McClelland, M. M., Cameron, C. E., Connor, C. M., Farris, C. L., Jewkes, A. M., \& Morrison, F. J. (2007). Links between behavioral regulation and preschoolers' literacy, vocabulary, and math skills. Developmental Psychology, 43, 947-959. 
McLoyd, V. C. (1990). The impact of economic hardship on black families and children: Psychological distress, parenting and socioemotional development. Child Development, 61, 311-346.

McLoyd, V. C. (1998). Socioeconomic disadvantage and child development. American Psychologist, 53, 185-204.

McEwen, B. S. (2000). The neurobiology of stress: From serendipity to clinical relevance. Brain Research, 886, 172-189.

Mezzacappa, E. (2004). Alerting, orienting, and executive attention: developmental properties and sociodemographic correlates in an epidemiological sample of young, urban children. Child Development, 75, 1373-1386.

Mischel, W., Shoda, Y., \& Rodriguez, M. L. (1989). Delay of gratification in children. Science, 244, 933-938.

Noble, K. G., Farah, M. J., \& McCandliss, B. M. (2006). Socioeconomic background modulates cognition-achievement relationships in reading. Cognitive Development, 21 (3): 349-368.

Noble, K. G., McCandliss, B. D., \& Farah, M. J. (2007). Socioeconomic gradients predict individual differences in neurocognitive abilities. Developmental Science, 10(4): 464-480.

Noble, K. G., Norman, M. F., \& Farah, M. J. (2005). Neurocognitive correlates of socioeconomic status in kindergarten children. Developmental Science, 8, 74-87.

Phillips D. A., Voran M., Kisker E., Howes C., \& Whitebook M. (1994). Child care for children in poverty: opportunity or inequity? Child Development, 65, 472-492.

Pianta R. C., La Paro K. M., Payne C., Cox M. J., \& Bradley R. (2002). The relation of kindergarten classroom environment to teacher, family, school, characteristics, and child outcomes. The Elementary School Journal, 102, 225-239.

Posner, M. I., \& Rothbart, M. K (2005). Influencing brain networks: Implications for education. Trends in Cognitive Sciences, 9, 99-103.

Rosenzweig, M. R., (2003). Effects of differential experience on the brain and behavior. Developmental Neuropsychology, 24, 523-540.

Rueda, M. R., Fan, J., McCandliss, B. D., Halparin, J. D., Gruber, D. B., Lercari, L. P., et al. (2004). Development of attentional networks in childhood. Neuropsychologia, 42, 1029-1040.

Schiff, M., \& Lewontin, R. (1986). Education and Class: The Irrelevance of IQ Genetic Studies. Oxford, UK: Clarendon Press.

Surkan, P. J., Zhang, A., Trachtenberg, F., Daniel, D. B., McKinlay, S., \& Bellinger, D. C. (2007). Neuropsychological function in children with blood lead levels $<10$ microg/dL. Neurotoxicology, 28, 1170-1177.

Turner, R. J., \& Avison, W. R. (2003). Status variations in stress exposure: implications for the interpretation of research on race, socioeconomic status, and gender. Journal of Health and Social Behavior, 44, 488-505.

van Praag, H., Kempermann, G., \& Gage, F. H. (2000) Neural consequences of environmental enrichment. Nature Reviews Neuroscience, 1, 191-198.

Wagner, R. K., \& Torgesen, J. K. (1987). The nature of phonological processing and its causal role in the acquisition of reading skills. Psychological Bulletin, 101, 192-212.

Wallach, L., Wallach, M. A., Dozier, M. G., \& Kaplan, N. E. (1977). Poor children learning to read do not have trouble with auditory discrimination but do have trouble with phoneme recognition. Journal of Educational and Psychology, 69, 36-39.

Weber, M. (1961 first published in 1923). General economic history. New York: Collier.

Whitehurst, G. J. (1997). Language processes in context: Language learning in children reared in poverty. In L. B. Adamson \& M. A. Romski (Eds.), Research on communication and language disorders: Contribution to theories of language development (pp. 233-266). Baltimore, MD: Brookes. 
632

633

634

635

636

637

638
Q. No.

\section{Query}

AQ1 Please check if edits to the sentence beginning "By guiding me ..." convey the intended meaning.

AQ2 Please check if 'test' should be changed to 'tested' in the sentence beginning "The tasks that ..." to convey the appropriate meaning.

AQ3 "Adler et al., 1997" has been changed to "Adler et al., 1994" as per the reference list. Please Check.

AQ4 "Hurt et al., 1995" is not given in the list. Please provide reference entry or delete citation.

AQ5 Please provide Volume ID for this reference.

AQ6 Please provide Volume ID, Pages for this reference.

AQ7 Please update.

AQ8 "Frank, Augustyn, Knight, Pell, Zuckerman, 2001" reference is not cited in the text. Please provide citation or delete from list.

AQ9 Please update.

AQ10 "Kass, 2003" reference is not cited in the text. Please provide citation or delete from list.

AQ11 Please provide remaining authors. 